\title{
Global recrystallisation model of low carbon sheet steels with different
}

\section{cementite contents}

\author{
T. De Cock, C. Capdevila, F.G. Caballero and C. García de Andrés \\ Materalia Group, Department of Physical Metallurgy, Centro Nacional de Investigaciones Metalúrgicas, \\ Consejo Superior de Investigaciones Científicas (CENIM-CSIC), Avda. Gregorio del Amo, 8, 28040 \\ Madrid, Spain.
}

Keywords: recrystallisation, ferritic steels, cementite, isothermal annealing.

\begin{abstract}
This paper discusses the influence of Particle Stimulated Nucleation (PSN) on the overall process of nucleation and subsequent grain growth in low carbon (LC) steels and proposes a global recrystallisation kinetics model based on fundamental physical metallurgy principles. The model takes into account the cementite content, which is dependent on the nominal carbon content, and the second phase particle size. The deformation field around cementite particles and its influence on recrystallisation processes is analysed. Finally, experimental evidence is given to show the accuracy of the theoretical predictions.
\end{abstract}

\section{Introduction}

In conventional processing, cold rolled steel is fully recrystallised by annealing, restoring ductility but lowering strength. If higher strength is demanded, this is achieved by either alloying the steel or by special heat treatments at higher temperatures. Conventional processing entails wastage of energy and increased costs. Alternatively, controlled low temperature annealing can restore ductility while conserving acceptably high strength levels, but requires a sound knowledge of the static recrystallisation of ferrite. 
The formation of strain-free grains during the static recrystallisation of cold-rolled ferritic steels is essentially a contest between two nucleation mechanisms: on the one hand new grains nucleate at deformed grain boundaries, yielding a final texture which is ideal for deep-drawing applications [1]; while on the other hand the presence of coarse cementite particles provides preferential sites for the nucleation of recrystallised grains with a texture close to random crystallographic orientation [2]. This is because second phase particles are surrounded by a randomly oriented deformation zone with higher dislocation densities than in the regions further away [3]. Thus the stored energy is higher in the vicinity of the precipitates, increasing the driving force for recrystallisation.

The influence of cementite has rarely been considered in kinetic models for static recrystallisation, even though it has a prominent influence on the evolution of the recrystallised volume fraction during isothermal annealing. Ørsund and Nes [4] described the variation in the growth rate caused by strain gradients, but their model did not include details of precipitation, such as its distribution.

This paper presents a recrystallisation model for cold rolled low carbon steels with considerable cementite contents, based on classic modelling by Johnson and Mehl [5], Avrami [6] and Kolmogorov [7] (JMAK theory). The role of carbide precipitation is included in the new model by means of two different parameters: firstly the nominal carbon content of the steel, which determines the amount of cementite precipitated; and secondly the coiling temperature, which defines its morphology.

\section{Materials and methods}

The full chemical composition of commercial hot rolled low carbon steel strips studied (among them the hereafter named steels A, C and E) and their thermomechanical processing route have been reported elsewhere [8]. In these steels different coiling temperatures (CT) were chosen, since this parameter is known to have an important effect on the morphology and distribution of the particles [9-11]. Two different carbon contents (steel C with carbon content of 0.08 wt. $\%$ vs. 0.014 wt. $\%$ for 
steels A and E) and CT (steel E with a CT of $550{ }^{\circ} \mathrm{C}$ vs. $740{ }^{\circ} \mathrm{C}$ for steels A and C) have been selected.

In order to validate the new kinetic model designed in this work a cold-rolling and coiling simulation of two different steels was performed in the conditions listed in Table 1. The annealing treatments consisted of heating at $20^{\circ} \mathrm{C} / \mathrm{s}$, holding at $620^{\circ} \mathrm{C}$ for between 5 and $100 \mathrm{~s}$, and final quenching. For metallographic examination, the specimens for light optical microscopy (LOM) analysis were etched with $2 \%$ nital solution for $35-45 \mathrm{~s}$ and the presence of cementite was disclosed with picral reagent [12]. The recrystallised volume fraction was measured experimentally using standard point-count methods.

An electropolishing procedure was carried out, using a 90\% glacial acetic acid and 10\% perchloric acid solution at $15^{\circ} \mathrm{C}$ and $17 \mathrm{~V}$, in order to study the early stages of recrystallisation by electron channelling contrast (ECC) [13] with field emission gun scanning electron microscopy (FEG-SEM). Texture measurements were performed by means of the Schulz reflection method using a D-5000 X-ray diffractometer furnished with an opened Eulerian cradle. Details of both the diffractometer and the analysis method have been given elsewhere [14]. The pole figures (110), (200) and (211) were measured and a series expansion technique was employed to calculate the orientation distribution function (ODF), along with ghost correction [15]. The typical cold rolling and recrystallisation textures of LC steels may be described by two texture fibres: an incomplete $\alpha$-fibre characterised by $<110>$ parallel to $\mathrm{RD}$; and a complete $\gamma$-fibre which comprises all crystals with $\{111\}$ plane parallel to ND [16].

The local orientation measurements on electropolished ( $90 \%$ glacial $+10 \%$ perchloric acid solution) samples were performed by electron backscattered diffraction (EBSD) at Universidad Politécnica de Valencia. EBSD patterns were generated at an acceleration voltage of $20 \mathrm{kV}$ and collected using an Oxford Instruments CRYSTAL detector mounted on a Jeol JSM 6300 SEM. The indexation of Kikuchi lines was performed with INCA software developed by Oxford Instruments. 
Finally, nanohardness measurements were carried out with a Hysitron nanoindenter system (TriboIndenter). This instrument has been described elsewhere [17], and for the present experiments a maximum charge of $800 \mu \mathrm{N}$ and a trapezoid load function was applied.

\section{Results and Discussion}

\section{Recrystallisation kinetics}

The experimentally determined evolution of the recrystallised volume fraction of steels $\mathrm{A}, \mathrm{C}$ and $\mathrm{E}$ revealed that higher carbon content leads to acceleration of the recrystallisation process (Fig. 1). A lower coiling temperature also yields higher recrystallised volume fractions, though to a lesser extent $[8]$.

This behaviour is closely related with the cementite precipitation process previously reported by the authors [18] and can be seen in Fig. 2. A higher carbon content leads to a higher volume fraction of cementite (steel C in Fig. 2(b) vs. steel A in Fig. 2(a)), while a lower CT produces a finer precipitate distribution (steel E in Fig. 2(c)). In steel A the CT is higher than the solubility temperature, so carbon can migrate to the grain boundaries and precipitate as cementite. However, when steels are coiled below the solubility temperature (steel E) not all the carbon precipitates and a certain amount remains in the solid solution [19].

Therefore, steels A, C and E shown in Fig. 2 present different combinations of the amount (volume fraction) and size (coarse or fine precipitates) of cementite precipitation. Such precipitates are located at the ferrite-ferrite grain boundaries and homogeneously distributed throughout the microstructure (see FEG-SEM images in Fig. 3).

\section{Nucleation on cementite particles}

Figure 3 shows an ECC image which illustrates an area of steel $\mathrm{C}$ with cementite after annealing at $620{ }^{\circ} \mathrm{C}$ for $6 \mathrm{~s}$. The cementite particles can be clearly observed together with the recrystallised 
grains nearby. This image shows that the regions adjacent to the coarse cementite particles, which have precipitated at the grain boundaries, constitute preferential sites for the nucleation of strainfree grains. It can also be seen that the areas labelled as (3) in Fig. 3 are characterised by larger deformations and internal misorientations than the surrounding grains (4). This is confirmed by the EBSD measurements shown in Fig. 4, where the existence of deformed areas is indicated by regions of low angle boundaries (misorientations $<10^{\circ}$ ). This is an important observation since the presence of local misorientation gradients, which is related with the stored energy, is a necessary condition for the activation of nucleation [20-21].

Therefore, it is clear that recrystallisation is triggered in the areas around cementite particles. Likewise, as is indicated in Figs. 1 and 2, both the amount and size of precipitates affect the recrystallisation process. In this sense, steels $\mathrm{A}, \mathrm{B}$ and $\mathrm{C}$ show a progressive increase in recrystallisation kinetics due to the higher volume fraction of cementite present in the microstructure [8]. Moreover, an increase in recrystallisation kinetics is detected with the subsequent decrease in CT in steels with a finer precipitate distribution [8].

Thus there is a clear correlation between the amount and size of cementite particles on the one hand and the recrystallisation kinetics on the other. This observation is related with the deformation field in the ferrite matrix which surrounds the cementite particles, as is demonstrated by means of the nanohardness measurements presented in Fig. 5. A hardness map is obtained from the nanohardness measurements performed. The results can be summarised as listed in Table 2, indicating that the local hardness increases when ferritic areas near the particles are studied. Since deformation is the driving force for the onset of nucleation, recrystallisation is prone to occur in areas with a higher (local) hardness.

Strengthening of the matrix surrounding the cementite particles could also explain why the observed recrystallisation kinetics are faster in steel $\mathrm{C}$ than in steel $\mathrm{E}$, since a coarse particle is surrounded by a deformation zone with a higher dislocation density than a fine particle [22]. 


\section{Orientation effect}

Cementite particles have a significant influence not only on the nucleation process but also on the evolution of texture during the recrystallisation process. This can be seen in the X-ray texture measurements of Fig. 6 .

From these diffraction measurements it can be deduced that the nucleation and growth mechanism is similar in all the steels. The as-received microstructure, consisting mainly of grains belonging to the $\alpha$-fibre (components with direction $<110>$ parallel to the rolling direction) and $\gamma$-fibre (components with their $\{111\}$ planes parallel to the rolling plane), evolves to a final texture with a strong $\gamma$-fibre. This can be explained by considering two types of nucleation: $\gamma$-type and random type, the relative weight of each determining the intensity of the $\{111\}$-component in the final microstructure.

As is shown in Fig. 6, the $\gamma$-fibre strengthens progressively at increasing coiling temperatures. This can be explained by the fact that a higher coiling temperature induces coarser and more widely dispersed carbides, which is favourable for the development of the $\gamma$-fibre due to the purity of the ferrite matrix regarding the carbon [23]. During coiling of the hot strip carbon is almost completely removed from the ferritic phase, since any residual carbon is precipitated in the form of cementite. If the carbides are widely spaced and the steel is heated rapidly after cold rolling, recrystallisation of the ferrite can take place before any significant re-dissolution occurs. The resulting texture contains a strong $\{111\}$-component (Fig. 6(b) vs. Fig. 6(f), i.e. steel A vs. E).

However, this argument cannot account for the differences observed between steels C and A (Figs. 6(d) and 6(b)), which have the same coiling temperature of $740{ }^{\circ} \mathrm{C}$, i.e. well above $700^{\circ} \mathrm{C}$. The only difference between these steels is the higher volume fraction of coarse cementite particles in steel C than in steel A. An explanation for the different $\gamma$-fibre intensities in this case can be found in the experimentally observed randomisation effect of grains nucleated near particles [2], which is confirmed by the local orientation measurements shown in Fig. 7. In this figure, illustrating the local 
orientations of the partly recrystallised steel $\mathrm{C}$, it can be clearly observed that the recrystallised grains near the cementite (black) have a random texture (Fig. 7(c)), whereas the grains that nucleated at the grain boundaries belong predominantly to the $\{111\}$-fibre (blue) (Fig. $7(\mathrm{~b})$ ). The orientation of recrystallised grains nucleated on cementite particles is random, since deformation zones have random orientations. Since fragmented cementite particles are aligned on the grain boundary of the deformed grain, these randomly oriented recrystallised grains also form elongated bands lying in the same direction and positioned on the grain boundaries (see recrystallised grains nucleated near cementite particles in Figs. 2 and 7). Thus, because of the higher volume fraction of cementite in steel $\mathrm{C}$ compared to steel $\mathrm{A}$, the $\gamma$-fibre in the former is less intense.

The volume fraction of $\{111\}$ fibre is calculated from experimental texture measurements as indicated below. For a given plane $\{h \mathrm{hl}\}$, two eulerian angles $\Phi^{\mathrm{hkl}}$ and $\varphi_{2}^{\mathrm{hkl}}$ are fixed, whereas $\varphi_{1}^{\mathrm{hkl}}$ can have any value within $(0, \pi / 2)$. The values of $\Phi^{\mathrm{hkl}}$ and $\varphi_{2}^{\mathrm{hkl}}$ can be calculated with

$$
\begin{aligned}
& \varphi_{2}^{\mathrm{hkl}}=\arctan \left(\frac{\mathrm{k}}{\mathrm{h}}\right) \\
& \Phi^{\mathrm{hkl}}=\arctan \left(\frac{\sqrt{\mathrm{h}^{2}+\mathrm{k}^{2}}}{1}\right)
\end{aligned}
$$

The volume fraction $\left(\mathrm{V}^{\mathrm{hkl}}\right)$ of this plane is given by

$$
\mathrm{V}^{\mathrm{hkl}}=\frac{4 \Delta \Phi \Delta \varphi_{2}}{\pi^{2}} \int_{0}^{\pi / 2} \mathrm{f}\left(\varphi_{1}, \varphi_{2}^{\mathrm{hkl}}, \Phi^{\mathrm{hkl}}\right) \sin \left(\Phi^{\mathrm{hkl}}\right) \mathrm{d} \varphi_{1}
$$

Since the orientation distribution function measured in our laboratory is given in a 5 - degree-mesh, the integration of equation (3) is really only carried out by summarisation as follows 
$\mathrm{V}^{\mathrm{hkl}}=\frac{4 \Delta \Phi \Delta \varphi_{2} \Delta \varphi_{1}}{\pi^{2}}\left[\sum_{\Phi^{\mathrm{hkl}}-5}^{\Phi^{\mathrm{hkl}}+5} \sum_{\varphi_{2}^{\mathrm{hkl}}-5}^{\mathrm{hkl}}+5 \sum_{\varphi_{1}=5}^{\varphi_{1}=90} \mathrm{f}\left(\varphi_{1}, \varphi_{2}^{\mathrm{hkl}}, \Phi^{\mathrm{hkl}}\right) \sin \left(\Phi^{\mathrm{hkl}}\right)\right]$

with $\Delta \Phi=\Delta \varphi_{2}=\Delta \varphi_{1}=5 \pi / 180$ [22]. These observations can be summarised in Table 3 .

In view of previously presented experimental results, the modelling of two types of nucleation should thus be taken into account: on the one hand the "standard" $\gamma$-class grain boundary nucleation, and on the other hand grains nucleated by PSN, which induce more random textures (Fig. 7). This twofold nucleation and grain growth process will be modelled in the next section.

\section{Modelling the influence of cementite on recrystallisation kinetics}

The concept of the extended volume [6] is very useful in this context, since it allows the differentiation of recrystallised grains nucleated at grain boundaries and those originated near cementite particles:

$\mathrm{X}_{\mathrm{ex}}=\mathrm{X}_{\mathrm{ex}}^{\mathrm{gb}}+\mathrm{X}_{\mathrm{ex}}^{\mathrm{cem}}$

Where $\mathrm{X}_{\mathrm{ex}}$ denotes the recrystallised volume fraction in the extended space (i.e. considering the grains as overlapping and interpenetrating objects) and 'gb' and 'cem' refer respectively to the grain boundaries and cementite as nucleation sites.

Calculations for the scenario without cementite

Recrystallisation kinetics is firstly studied without taking into account any effect of cementite particles. In this case, the extended recrystallised volume fraction is the sum of the contribution of recrystallised $\{111\}$ and $\{h k 1\}$ grains: 
$\mathrm{X}_{\mathrm{ex}}^{\mathrm{gb}}=\mathrm{X}_{\mathrm{ex}}^{\{11\}, \mathrm{gb}}+\mathrm{X}_{\mathrm{ex}}^{\{\mathrm{hkl}\}, \mathrm{gb}}$

where $X_{\mathrm{ex}}^{\mathrm{gb}}$ is the total recrystallised volume fraction for grain boundary nucleation and $\mathrm{X}_{\mathrm{ex}}^{\{111, \mathrm{gb}}$ and $\mathrm{X}_{\mathrm{ex}}^{\{\mathrm{hkl}\}, \mathrm{gb}}$ are the contributions for $\gamma$-type and random type nucleation, respectively. The corresponding calculation is based on the classic JMAK-model, considering a nucleation rate [24]

$$
\dot{\mathrm{N}}=A \varepsilon^{4} \mathrm{~S}_{\mathrm{V}} \exp \left(-\frac{\mathrm{Q}_{\mathrm{N}}}{\mathrm{RT}}\right)
$$

where $A$ is a composition-dependent parameter, $\mathrm{Q}_{\mathrm{N}}$ the activation energy for nucleation, $\mathrm{R}$ the gas constant, $T$ the absolute temperature, $\mathrm{S}_{\mathrm{V}}$ the specific area of grain boundary of the deformed material, calculated experimentally by a point-counting method, and $\varepsilon$ is the true strain, which is calculated as

$$
\varepsilon=\frac{2}{\sqrt{3}} \ln \left(\frac{100}{100-\mathrm{CR}}\right)
$$

where CR stands for reduction during cold rolling in percentage.

As has been reported elsewhere [22], two types of cases can be differentiated for the compositiondependent parameter $\mathrm{A}$ of equation (7): steels with low and with high solute carbon contents $\left([\mathrm{C}]^{\mathrm{sol}}\right)$. Since high $[\mathrm{C}]^{\text {sol }}$ values deteriorate $\{111\}$-type nucleation, the nucleation rate for both cases can be written as:

$$
\dot{\mathrm{N}}^{\{111\}}=\mathrm{a} \varepsilon^{4} \mathrm{~S}_{\mathrm{V}} \exp \left(-\frac{\mathrm{Q}_{\mathrm{N}}}{\mathrm{RT}}\right)
$$


for $\{111\}$-type nucleation, and

$$
\dot{\mathrm{N}}^{\{h \mathrm{kl}\}}=\left(\mathrm{a}-\mathrm{b}[\mathrm{C}]^{\mathrm{sol}}\right) \varepsilon^{4} \mathrm{~S}_{\mathrm{V}} \exp \left(-\frac{\mathrm{Q}_{\mathrm{N}}}{\mathrm{RT}}\right)
$$

for $\{\mathrm{hkl}\}$-type nucleation. In these equations, a and $\mathrm{b}$ are fitting constants, whereas the solid carbon content $[\mathrm{C}]^{\text {sol }}$ was experimentally determined for the studied steels and listed in Table 4 [19]. In this respect it should be taken into account that the observed recrystallisation times are very short (typically less than $1 \mathrm{~min}$ ) and that in these time intervals it is assumed that the cementite content is not altered, i.e. $[\mathrm{C}]^{\text {sol }}$ is constant and equal to the content measured at the onset of recrystallisation. On the other hand, a time-dependent isotropic growth rate $\mathrm{G}$ is considered, which is assumed to be identical for both types of grain boundary nucleation. The temporal variation in the growth rate is confirmed by the latest experimental observations, which shows that the grain growth rate decreases with time [25] and will be validated hereafter. Thus an expression of the following type is assumed:

$$
\mathrm{G}=\mathrm{B} \varepsilon \mathrm{t}^{-\mathrm{r}} \exp \left(-\frac{\mathrm{Q}_{\mathrm{G}}}{\mathrm{RT}}\right)
$$

where $\mathrm{B}$ is another fitting constant, $\mathrm{Q}_{\mathrm{G}}$ the activation energy for grain growth and $\mathrm{r}$ is a temperatureindependent parameter. The recrystallised fraction of grains nucleated at the grain boundaries can then be expressed as

$$
\mathrm{X}_{\mathrm{ex}}^{\mathrm{gb}}(\mathrm{t})=\int_{0}^{\mathrm{t}} \mathrm{V}(\mathrm{t}-\tau) \dot{\mathrm{N}}^{\{\mathrm{nuc}\}} \mathrm{d} \tau
$$

where $\{$ nuc $\}$ stand for $\{111\}$ or $\{h k l\}$, depending on the nucleation type, and 
$V(t-\tau)=K\left(\int_{0}^{t} G\left(t^{\prime}\right) d t^{\prime}\right)^{3}$

where $\mathrm{K}$ is a geometrical factor describing the morphology of the growing grain (for spherical growth type $\mathrm{K}=4 \pi / 3)$.

Finally, appropriate impingement modelling should be carried out, relating the extended recrystallised volume fraction and the real values. According to [26] the best fit in the case of clustered nucleation is obtained by the following equation:

$$
\mathrm{X}_{\mathrm{V}}=\frac{\mathrm{X}_{\mathrm{ex}}}{1+\mathrm{X}_{\mathrm{ex}}}
$$

Combining the equations for nucleation (7) and grain growth (11) into equation (12) for both nucleation types and adding these contributions (as indicating in equation (6)), a total volume fraction of recrystallised grains can be obtained through (14), leading to the following expression after redefining the fitting constants (i.e. $(\mathrm{a}+\mathrm{c}) \mathrm{KB}^{3} \rightarrow \mathrm{a}$, and $\mathrm{bKB}^{3} \rightarrow \mathrm{b}$ ):

$$
\frac{\mathrm{X}_{\mathrm{V}}}{1-\mathrm{X}_{\mathrm{V}}}=\left(2 \mathrm{a}-\mathrm{b}[\mathrm{C}]^{\text {sol }}\right) \varepsilon^{7} \mathrm{~S}_{\mathrm{V}} \mathrm{t}^{4-3 \mathrm{r}} \exp \left(-\frac{\mathrm{Q}_{\mathrm{ReX}}}{\mathrm{RT}}\right)
$$

where $\mathrm{Q}_{\mathrm{ReX}}$ is the sum of the energy contributions for nucleation and grain growth. The parameter $\mathrm{r}$, expressing the temporal dependence of grain growth, can then easily be experimentally determined using the following relation:

$\ln \left(\frac{X_{V}}{1-X_{V}}\right) \propto(4-3 r) \ln t$ 
The experimental validation of the above expression showed that the value of $r$ oscillates between 0.1 and 0.4 , which validates the hypothesis of time-dependent grain growth, since a constant grain growth process would lead to the observation of $r=0$ (equation (11)).

\section{Calculations including the influence of cementite}

The influence of the cementite on the total recrystallised fraction can be expressed according to the following equation:

$\mathrm{X}_{\mathrm{ex}}=\mathrm{X}_{\mathrm{ex}}^{\mathrm{gb}}+\mathrm{X}_{\mathrm{ex}}^{\mathrm{cem}}=\mathrm{X}_{\mathrm{ex}}^{\{111\}, \mathrm{gb}}+\mathrm{X}_{\mathrm{ex}}^{\{\mathrm{hkl} 1\} \mathrm{gb}}+\mathrm{X}_{\mathrm{ex}}^{\{\mathrm{hkl}\}, \mathrm{cem}}$

For this purpose a grain occupation degree $(\mathrm{GOD}), \mathrm{f}_{\mathrm{v}}^{\mathrm{cem}}$, is defined as the fraction of the total grain boundary volume where cementite has precipitated, and is calculated experimentally using a pointcount method:

$\mathrm{f}_{\mathrm{V}}^{\mathrm{cem}}=\frac{\mathrm{S}_{\mathrm{V}}^{\mathrm{cem}}}{\mathrm{S}_{\mathrm{V}}}$

where $\mathrm{S}_{\mathrm{V}}^{\mathrm{cem}}$ is the grain boundary surface per unit volume occupied by cementite. It is therefore assumed that nucleation at the grain boundaries occurs through the mechanism explained in the previous section (scenario without cementite), with a weight of the nucleation sites of $\left(1-\mathrm{f}_{\mathrm{V}}^{\text {cem }}\right) \mathrm{S}_{\mathrm{V}}$, whereas nucleation of the grains near the cementite has a weight of $\mathrm{f}_{\mathrm{V}}^{\mathrm{cem}} \mathrm{S}_{\mathrm{V}}$. Thus the value of $\mathrm{X}_{\mathrm{ex}}^{\{\mathrm{hkl}\} \text {,cem }}$ can be calculated according to equation (12), considering nucleation and growth rates equivalent to the case of grain boundary nucleation (equations (10) and (11)), but assuming that for 
grains nucleated at the grain boundaries $S_{V}$ in equation (10) should be replaced by $\left(1-f_{V}^{\text {cem }}\right) S_{V}$, and for grains nucleated at cementite particles it should be replaced by $f_{v}^{\text {cem }} S_{V}$.

With regard to the true strain in the vicinity of the cementite, it should be replaced by a local strain: $\varepsilon \rightarrow \varepsilon^{\text {local }}$, which accounts for the additional deformation introduced by the coarse particles [27]. The excess deformation near the cementite particles is obtained by means of the nanohardness measurements shown in Fig. 5 and whose results are summarised in Table 2. By comparison of the hardness values close to the cementite and the matrix values of the studied steels, an approximate value of $\varepsilon^{\text {local }} \approx 1.4 \varepsilon$ can be found.

Moreover, the faster growth rate of grains originated on the cementite particles should be taken into account, according to:

$\mathrm{G}^{\mathrm{cem}}=\mathrm{G}[1+\varphi(\rho)]$

where $G^{\text {cem }}$ is the isotropic grain growth of particles nucleated near the cementite, $G$ is defined according to equation (11), and $\varphi(\rho)$ is a factor that determines the acceleration of the grain growth process due to the higher local deformation and which depends on the cementite morphology, $\rho$, since small particles induce a lower $\varepsilon^{\text {local }}$ value than large ones. Due to the proper definition of the grain growth rate equation (19) can be rewritten as

$$
\frac{\mathrm{dR}_{\mathrm{ex}}^{\mathrm{cem}}}{\mathrm{dt}}=(1+\varphi) \frac{\mathrm{dR}_{\mathrm{ex}}^{\mathrm{gb}}}{\mathrm{dt}}
$$

where $\mathrm{R}_{\mathrm{ex}}^{\mathrm{cem}}$ and $\mathrm{R}_{\mathrm{ex}}^{\mathrm{gb}}$ are the unimpinged grain sizes nucleated near the cementite and at the grain boundaries, respectively. The following method has been employed to deduce an experimental value 
of $\varphi$ for each type of cementite. For clustered nucleation the real and extended recrystallised volume fractions are related as

$$
\frac{X_{\mathrm{V}}}{1-\mathrm{X}_{\mathrm{V}}}=\mathrm{X}_{\mathrm{ex}}
$$

and assuming a spherical shape, this expression can be rewritten as

$$
\frac{\frac{4}{3} \pi N_{V} R^{3}}{1-\frac{4}{3} \pi N_{V} R^{3}}=\frac{4}{3} \pi\left(N_{V}\right)_{e x} R_{e x}^{3}
$$

where $\mathrm{N}_{\mathrm{V}}$ and $\left(\mathrm{N}_{\mathrm{V}}\right)_{\text {ex }}$ are the number of nuclei per unit volume in real and extended space, respectively. Rios and Padilha [27] related this variable with the equivalent in the extended space:

$$
\frac{\mathrm{N}_{\mathrm{V}}}{\left(\mathrm{N}_{\mathrm{V}}\right)_{\mathrm{ex}}} \approx\left(\frac{\mathrm{X}_{\mathrm{V}}}{-\ln \left(1-\mathrm{X}_{\mathrm{V}}\right)}\right)^{2 / 3}
$$

Combining equations (20), (22) and (23) it can then be found that

$$
\frac{\mathrm{R}_{\mathrm{ex}}^{\mathrm{cem}}}{\mathrm{R}_{\mathrm{ex}}^{\mathrm{gb}}}=1+\varphi \approx \frac{\mathrm{R}^{\mathrm{cem}}}{\mathrm{R}^{\mathrm{gb}}} \sqrt{\frac{3-4 \pi\left(\mathrm{R}^{\mathrm{gb}}\right)^{3}\left(\mathrm{~N}_{\mathrm{V}}\right)^{\mathrm{gb}}}{3-4 \pi\left(\mathrm{R}^{\mathrm{cem}}\right)^{3}\left(\mathrm{~N}_{\mathrm{V}}\right)^{\mathrm{cem}}}}
$$

where the indices ' $\mathrm{gb}$ ' and 'cem' again refer to the grains nucleated at the grain boundaries and near the cementite particles, respectively. Equation (24) can be converted to 


$$
1+\varphi \approx \sqrt[3]{\frac{\left(\mathrm{X}_{\mathrm{V}}\right)^{\mathrm{cem}}}{\left(\mathrm{X}_{\mathrm{V}}\right)^{\mathrm{gb}}} \frac{1-\left(\mathrm{X}_{\mathrm{V}}\right)^{\mathrm{gb}}}{1-\left(\mathrm{X}_{\mathrm{V}}\right)^{\mathrm{cem}}} \frac{\left(\mathrm{N}_{\mathrm{V}}\right)^{\mathrm{gb}}}{\left(\mathrm{N}_{\mathrm{V}}\right)^{\mathrm{cem}}}}
$$

The application of this formula on steels $\mathrm{C}$ and $\mathrm{E}$, after a careful selection and measurement of both types of recrystallised grains, yields the results summarised in Fig. 8. An intermediate annealing temperature of $620^{\circ} \mathrm{C}$ was chosen in these experiments, and it can be seen that the maximum (steel C) and minimum values (steel E) obtained for $\varphi$ are relatively constant with annealing time, which shows that the hypothesis of a time-independent relation of $\varphi$ is valid.

Validation: Prediction of $\gamma$-fibre evolution

To validate this new model, both steels listed in Table 1 were studied experimentally and the volume fraction of recrystallised material was predicted with the new model, using the parameters listed in Table 5. The differences in cementite particle distribution and morphology are shown in Fig. 9. A comparison between predicted and measured volume fraction is shown in Fig. 10, where it can be observed that the recrystallised volume fraction is reasonably good predicted in those cases where cementite plays an important role. It can also be seen that a high coiling temperature and high cold rolling degree (steel VAL-2) leads to faster recrystallisation kinetics.

The presented model allows the predicting of the volume fraction of $\{111\}$ grains as a function of the carbon content and processing parameters such as the coiling temperature and degree of deformation. In this sense, $\mathrm{F}^{\{111\}}(\mathrm{t})$, is defined as:

$$
\frac{\mathrm{X}_{\mathrm{ex}}^{\{11\}, \mathrm{gb}}}{\mathrm{X}_{\mathrm{ex}}^{\{111\}, \mathrm{gb}}+\mathrm{X}_{\mathrm{ex}}^{\{\mathrm{hkl}\}, \mathrm{gb}}+\mathrm{X}_{\mathrm{ex}}^{\mathrm{cem}}}=\mathrm{F}^{\{111\}}(\mathrm{t})
$$


where $\mathrm{X}_{\mathrm{ex}}^{\{111, \mathrm{gb}}, \mathrm{X}_{\mathrm{ex}}^{\{\mathrm{hkl}\}, \mathrm{gb}}$ and $\mathrm{X}_{\mathrm{ex}}^{\mathrm{cem}}$ are the contributions to the total recrystallised fraction, in the extended space, of $\{111\}$ type nucleation at grain boundaries, $\{h k 1\}$ type nucleation at grain boundaries, and $\{\mathrm{hkl}\}$ type nucleation near the cementite particles, and $\mathrm{F}^{\{111\}}(\mathrm{t})$ is the fraction of $\{111\}$ type recrystallised grains. Choosing for $\mathrm{t}$ the value corresponding to full recrystallisation (i.e. $\mathrm{X}_{\mathrm{V}}=100 \%$ ), the values of the predicted $\{111\}$ fractions can be compared with the measured values of Table 3. The result of this comparison shows good agreement between both values for all the studied steels.

In Fig. 10 it can be seen that the model slightly underestimates the effect of coarse cementite particles on recrystallisation and overestimates the effect of fine cementite particles. This could be due to excessive simplification of the nucleation and impingement mechanism. Nevertheless, the predicted values are still within an acceptable range. Equation (26) can also be used to estimate the fraction of $\{111\}$ type recrystallised grains for each of the studied steels. This has been done for steels A, C and E and is represented in Fig. 11.

From this figure it can be deduced that the nucleation of recrystallised grains around the cementite (i.e. random orientation nucleation) leads to low fractions of $\mathrm{F}^{\{111\}}$ during the initial stages of the recrystallisation process. At later stages, the $\{111\}$-type nucleation dominates the process, leading to increasing values of $\mathrm{F}^{\{111\}}$. In steel A, with a low presence of particles, this effect is less pronounced, whereas in steel $\mathrm{C}$ the high cementite fraction gives rise to important variations in this parameter.

The calculation of $\{111\}$-type grains according with equation (26) has been extended to the validation steels (VAL-1 and VAL-2 steel, see Table 1). Figure 12 shows a comparison between both calculated and measured volume fraction of \{111-type grains obtained. It is clear that a reasonable agreement has been obtained.

\section{Conclusions}


Recrystallisation behaviour is studied in cold-rolled LC steels with considerable cementite contents, which are seen to accelerate the recrystallisation process. It is shown that a higher volume fraction of cementite (i.e. higher carbon content) leads not only to faster kinetics, but also to a finer particle distribution. An overall recrystallisation model is proposed which takes into account experimentally verified variables such as time-dependent grain growth, the amount and size of particles, the acceleration of recrystallised grain growth in the case of nucleation near cementite particles, and the solute carbon content. This model affords a good correlation between calculated and experimental recrystallised volume fraction values. Moreover, the fraction of $\{111\}$-type recrystallised grains is predicted with reasonable accuracy.

\section{Acknowledgements}

The authors acknowledge the financial support from the European Union through the European Coal and Steel Community Programme (ECSC-7210-PR-368) and from the Spanish Ministerio de Educación y Ciencia (Special Action MAT 2002-10810-E). T. De Cock would also like to express his gratitude to the Consejo Superior de Investigaciones Científicas (CSIC) for financial support in the form of a Ph.D. research grant (I3P program). The authors would like to thank Prof. V. Amigó of the Mechanical Engineering Department of the Universidad Politécnica de Valencia for his collaboration with the EBSD measurements. The authors are grateful to M. Bögershausen of the Max Planck Institut für Eisenforschung in Dusseldorf (Germany) for his valuable help in the nanohardness experiments.

\section{References}

[1] B. Hutchinson, Int. Met. Rev. 29 (1984), pp. 25-42. 
[2] H. Inagaki, Z. Metallkde. 78 (1987), pp. 630-638.

[3] F.J. Humphreys, Acta Metall. 25 (1977), pp. 1323-1344.

[4] R. Ørsund and E. Nes, Scr. Metall. 22 (1988), pp. 671-679.

[5] W. A. Johnson and R. F. Mehl, Trans. AIME 135 (1939), p. 416-442.

[6] M. Avrami, J. Chem. Phys. 7 (1939), pp. 1103-1112.

[7] A. N. Kolmogorov, Izv. Akad. Nauk. USSR Ser. Matemat.. 1 (1937), pp. 355-372.

[8] C. Capdevila, T. De Cock, F.G. Caballero and C. Garcia de Andrés, Mat. Sci. Forum 550 (2007), pp. 595-600.

[9] C. Capdevila, C.G. de Andres and F.G. Caballero, Scr. Mater. 44 (2001), pp. 129-134.

[10] O.N. Yakubovsy, L.M. Storojeva, D.A. Burko, V.P. Barytinsky and J.I. Larin, in: 41st MWSP CONF, I. Sadler (ed.), ISS, Baltimore, 1999, pp. 245-251.

[11] H. Kubotera, K. Nakaoka, K. Araki, K. Watanabe and K. Iwasa, Tesu-to-Hagane 62 (1976), pp. $846-855$.

[12] F.S. Lepera, Journal of Metals 32 (1980), pp. 38-39.

[13] C.W. Oatley, The scanning electron microscope, Cambridge University Press, Cambridge, 1972.

[14] T. De Cock, JP Ferrer, C. Capdevila, F.G. Caballero, V. Lopez and C. Garcia de Andrés, Scr. Mater. 55 (2006), pp. 441-443.

[15] H. J. Bunge, Texture Analysis in Materials Science - Mathematical Methods, Butterworths \& Co., New York, 1982. 
[16] T. De Cock, C. Capdevila, F. G. Caballero and C. García de Andrés, Scr. Mater. 54 (2006), pp. 949-954.

[17] Y. Wang, D. Raabe, C. Klüber and F. Roters, Acta Mater. 52 (2004), pp. 2229-2238.

[18] C. Capdevila, T. De Cock, F.G. Caballero and C. Garcia de Andrés, Mater. Sci. Forum 500501 (2005), pp. 803-810.

[19] A. Pichler, C. Commenda, G. Hribering, A. Bodin, G. Bourdon, J. C. Herman, D. Artymowicz, Hutchinson, U. Lotter and L. Zhang. Improvement of cold rolled products by computer assisted metallurgical modelling, European Commission, Technical Steel Research Report, EUR21136EN, Bruxelles, 2004.

[20] G. Gottstein, D. A. Molodov, L. S. Shvindlerman, D. J. Srolovitz and M. Winning: Curr. Opin. Solid State Mater. Sci. 5 (2001), pp. 9-14.

[21] J. P. Ferrer, T. De Cock, C. Capdevila, F. G. Caballero and C. Garcia de Andrés, Acta Mater. 55 (2007), pp. 2075-2083.

[22] R. Bullough and L.C. Davis: Acta Metall. Mater. 43 (1995), pp. 2737-2742.

[23] K. Ushioda, U. Vonschlippenbach and W.B. Hutchinson, Textures Microstruct. 7 (1987), pp. $11-17$.

[24] M.R. Barnett, J.J. Jonas and P.D. Hodgson: 37th MWSP Conf. Proc., I. Sadler (ed.), ISS, Baltimore, 1996, pp. 971-978.

[25] D. Artymowicz, W.B. Hutchinson, P.J. Evans and G.J. Spurr, in: Int. Symp. Microalloying in Steels, B. Lopez, I. Gutierrez, J.M. Rodriguez-Ibabe (eds), Trans. Tech. Publications, San Sebastián, 1998, pp. 105-119. 
[26] F.J. Humphreys and M. Hatherly, Recrystallisation and Related Annealing Phenomena, Pergamon Press/Elsevier, Oxford, 1995.

[27] H. Inagaki, ISIJ Int. 34 (1994), pp. 313-321.

[28] P.R. Rios and A.F. Padilla, Scr. Mater. 48 (2003), pp. 1561-1564.

[29] K. Magee, K. Mukunthan and E.B. Hawbolt, in: Recrystallisation '90, T. Chandra (ed), TMS, Warrendale, 1990, pp. 393-398.

[30] A. Bodin, PhD Thesis, Technische Universiteit Delft, Delft, 2002. 


\section{Tables Captions}

Table 1. Chemical composition (in wt.-\%) and processing parameters of the steels used for validation.

Table 2. Nanohardness measurements in the studied steels

Table 3. Volume fractions (in \%) of the $\gamma$-type $\{111\}$ and random-type $\{\mathrm{hkl}\}$ components for steels A, C and $\mathrm{E}$ in the initial and fully recrystallised states.

Table 4. Cementite and solute carbon content for steels A, C and E.

Table 5. Parameters used in modelling at $620^{\circ} \mathrm{C}$. The activation energies for nucleation and grain growth have been combined into an overall activation energy for recrystallisation QReX. 


\section{Figure Captions}

Figure 1. Evolution of recrystallised volume fraction in steels A, C and E.

Figure 2. As-received microstructure of (a) steel A $\left(\mathrm{C}=0.014\right.$ wt.- $\%$ and $\left.\mathrm{CT}=740{ }^{\circ} \mathrm{C}\right)$ (b) steel C $\left(\mathrm{C}=0.08\right.$ wt. $\%$ and $\left.\mathrm{CT}=740{ }^{\circ} \mathrm{C}\right)$ and (c) steel $\mathrm{E}\left(\mathrm{C}=0.014\right.$ wt. $\%$ and $\left.\mathrm{CT}=550{ }^{\circ} \mathrm{C}\right)$. The cementite particles can be clearly disclosed. Microstructure for LOM is revealed with picral.

Figure 3. ECC image of steel $\mathrm{C}$ annealed at $620^{\circ} \mathrm{C}$ during 6 s. (1) Recrystallised grains nucleated at the cementite; (2) Cementite particles precipitated at the ferritic grain boundaries; (3) high deformation areas; (4) low deformation areas; (5) recrystallised grains nucleated at the grain boundaries.

Figure 4. EBSD measurements of the partially recrystallised steel $\mathrm{C}$ (annealing during $14 \mathrm{~s}$ at $620^{\circ} \mathrm{C}$ ). (a) IQ map of the selected region. (b) Misorientation map of the same region, indicating the low angle $\left(<10^{\circ}\right.$; green $)$ and high angle misorientations $\left(<45^{\circ}\right.$ yellow; $<60^{\circ}$ red $)$.

Figure 5. Micrograph and the corresponding nanohardness map in steel C.

Figure 6. $\varphi 2=45^{\circ}$ sections (Bunge notation) of ODFs of the as-received and fully recrystallised at $620^{\circ} \mathrm{C}$ steel A ((a) and (b)), steel C ((c) and (d)) and steel E ((e) and (f)), respectively. The colour scale of the orientation intensities ( $\mathrm{x}$ random) for all measurements is indicated at the right hand side of (f). 
Figure 7. (a) Local orientation measurements of the partially recrystallised steel C, annealed during $8 \mathrm{~s}$ at $620^{\circ} \mathrm{C}$. The black regions of the EBSD-image correspond to cementite particles; (b) and (c) represent the orientation distributions of the grains nucleated at grain boundaries and near the cementite, respectively. Note that image (b) includes some deformed (i.e. non-recrystallised) grains too.

Figure 8. Measurement of $\varphi$ in steels $\mathrm{C}$ and $\mathrm{E}$ at annealing temperature of $620^{\circ} \mathrm{C}$ for different annealing times.

Figure 9. As-received microstructure of (a) steel VAL-1 and (b) steel VAL-2. The cementite particles can be clearly disclosed. Microstructure for LOM is revealed with picral.

Figure 10. Prediction of evolution of the volume fraction recrystallised of the validation steels at $620^{\circ} \mathrm{C}$.

Figure 11. Evolution of the fraction $\{111\}$-type recrystallised grains during ongoing of the recrystallisation process for steels $\mathrm{A}, \mathrm{C}$ and $\mathrm{E}$.

Figure 12. Comparison between calculated and measured values of $\mathrm{F}^{\{111\}}(\mathrm{t})$ for VAL-1 and VAL-2 validation steels. 


\section{TABLES}

Table 1. Chemical composition (in wt.-\%) and processing parameters of the steels used for validation.

\begin{tabular}{lcccccccccc}
\hline & $\mathbf{C}$ & $\mathbf{S i}$ & $\mathbf{M n}$ & $\mathbf{P}$ & $\mathbf{S}$ & $\mathbf{A l}$ & $\mathbf{T i}$ & $\mathbf{N}$ & $\mathbf{C T}^{*}$ & $\mathbf{C R}^{* *}$ \\
\hline VAL-1 & 0.045 & 0.010 & 0.19 & 0.012 & 0.013 & 0.040 & 0.001 & 0.0037 & 500 & 59.6 \\
VAL-2 & 0.080 & 0.011 & 0.17 & 0.004 & 0.005 & 0.053 & 0.001 & 0.0040 & 650 & 80.1 \\
$* \mathbf{C T}=$ Coiling temperature in ${ }^{\circ} \mathrm{C}$ & & & & & & \\
$* * \mathbf{C R}=$ Cold reduction in thickness in $\%$ & & & &
\end{tabular}


Table 2. Nanohardness measurements in the studied steels

Location of the indent Average Hardness (GPa)

$\begin{array}{ll}\text { Ferrite matrix } & 4.07 \pm 0.48\end{array}$

$\begin{array}{ll}\text { Ferrite surrounding the cementite } & 6.09 \pm 0.74\end{array}$

$\begin{array}{ll}\text { Cementite } & 14.01 \pm 0.39\end{array}$ 
Table 3. Volume fractions (in $\%$ ) of the $\gamma$-type $\{111\}$ and random-type $\{h k l\}$ components for steels $\mathrm{A}, \mathrm{C}$ and $\mathrm{E}$ in the initial and fully recrystallised states.

\begin{tabular}{ccccc}
\hline Steel & \multicolumn{2}{c}{ As-rolled } & \multicolumn{2}{c}{ As-recrystallised } \\
& $\mathrm{V}_{\{111\}}$ & $\mathrm{V}_{\{\mathrm{hk}\}}$ & $\mathrm{V}_{\{111\}}$ & $\mathrm{V}_{\{\mathrm{hk} 1\}}$ \\
\hline $\mathrm{A}$ & 80.4 & 19.6 & 88.9 & 11.1 \\
$\mathrm{C}$ & 80.8 & 19.2 & 84.8 & 15.2 \\
$\mathrm{E}$ & 80.0 & 20.0 & 76.2 & 23.8 \\
\hline
\end{tabular}


Table 4. Cementite and solute carbon content for steels A, C and E.

\begin{tabular}{cccccc}
\hline Steel & \%C (wt.\%) & $\mathrm{CT}\left({ }^{\circ} \mathrm{C}\right)$ & \% ferrite & \% cementite & {$[\mathrm{C}]^{\text {sol }}(\mathrm{ppm})$} \\
\hline $\mathrm{A}$ & 0.014 & 740 & 99.80 & 0.20 & 20 \\
$\mathrm{C}$ & 0.080 & 740 & 98.86 & 1.14 & 38 \\
$\mathrm{E}$ & 0.014 & 550 & 99.80 & 0.20 & 39 \\
\hline
\end{tabular}


Table 5. Parameters used in modelling at $620^{\circ} \mathrm{C}$. The activation energies for nucleation and grain growth have been combined into an overall activation energy for recrystallisation $Q_{\mathrm{ReX}}$.

\begin{tabular}{ccc}
\hline & VAL-1 & VAL-2 \\
\hline $\mathrm{S}_{\mathrm{V}}\left(\mathrm{mm}^{-1}\right)$ & 6.210 & 3.832 \\
$\varphi$ & 0.24 & 0.4 \\
$\varepsilon$ & 1.15 & 1.86 \\
$\varepsilon^{\text {local }}$ & 1.71 & 2.30 \\
$\mathrm{f}_{\mathrm{v}}^{\text {cem }}$ & 0.23 & 0.26 \\
$\mathrm{a}$ & $8.04 \times 10^{-5}$ & $8.04 \times 10^{-5}$ \\
$\mathrm{~b}$ & $2.38 \times 10^{-2}$ & $2.38 \times 10^{-2}$ \\
$4-3 \mathrm{r}$ & 3.04 & 3.04 \\
$\mathrm{Q}_{\mathrm{ReX}}(\mathrm{kJ} / \mathrm{mol})[29,30]$ & 277 & 277 \\
\hline
\end{tabular}


Figure 1
Click here to download high resolution image

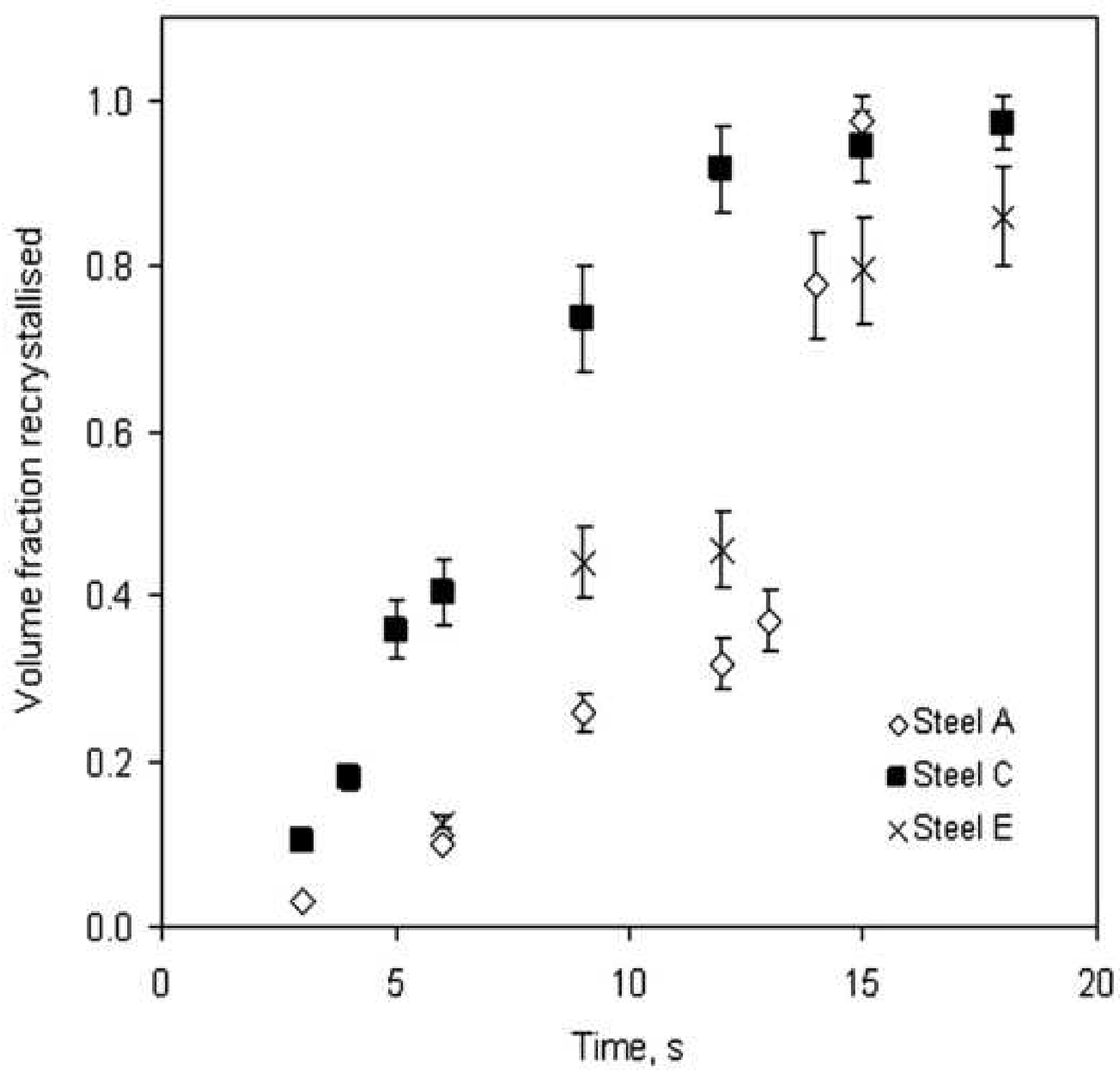


Figure 2
Click here to download high resolution image
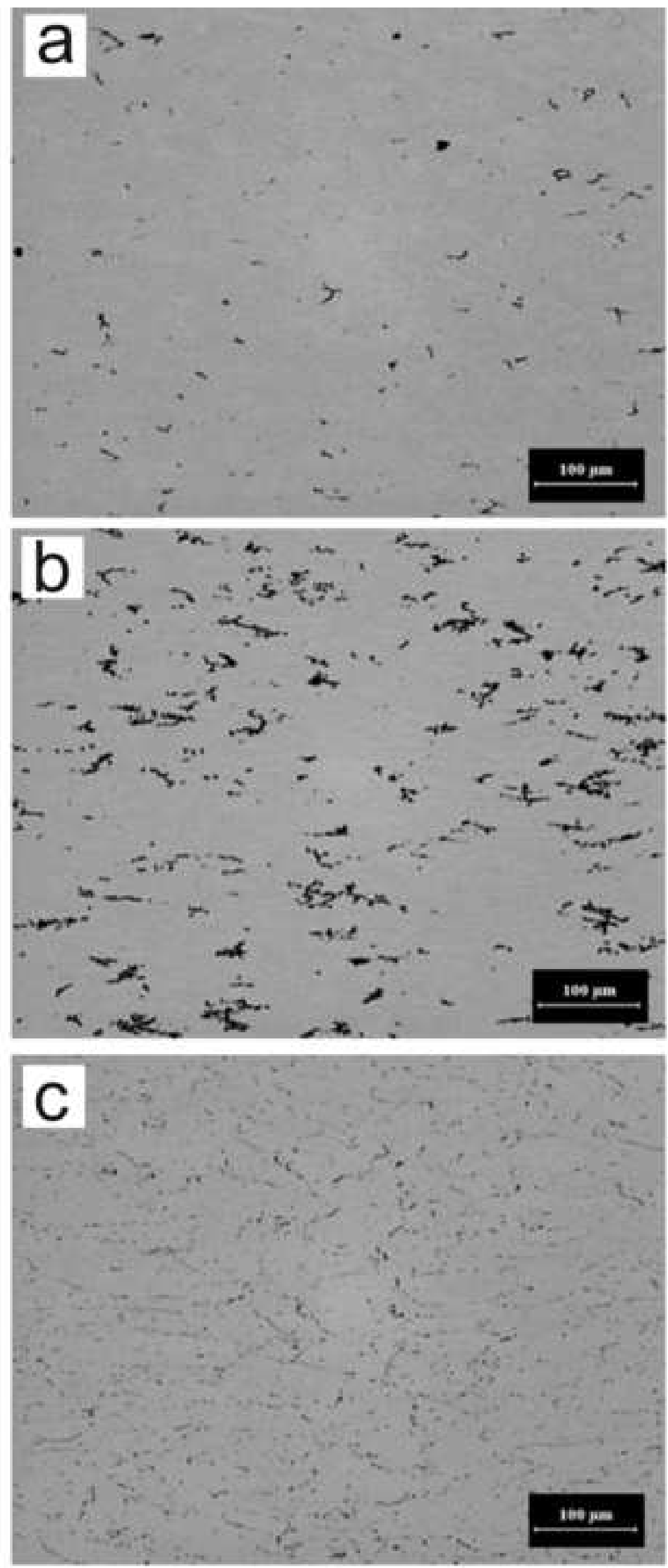
Click here to download high resolution image

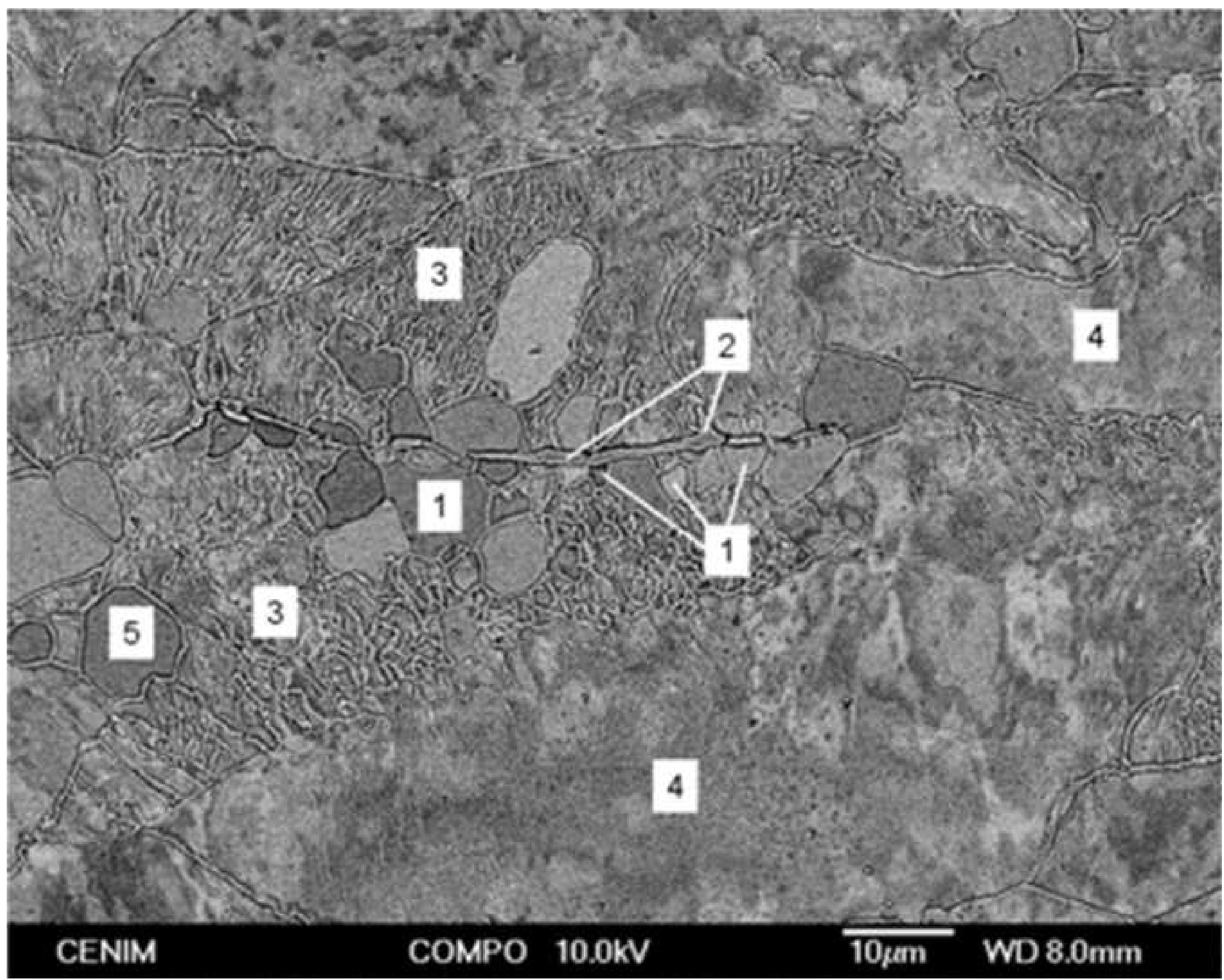


Click here to download high resolution image

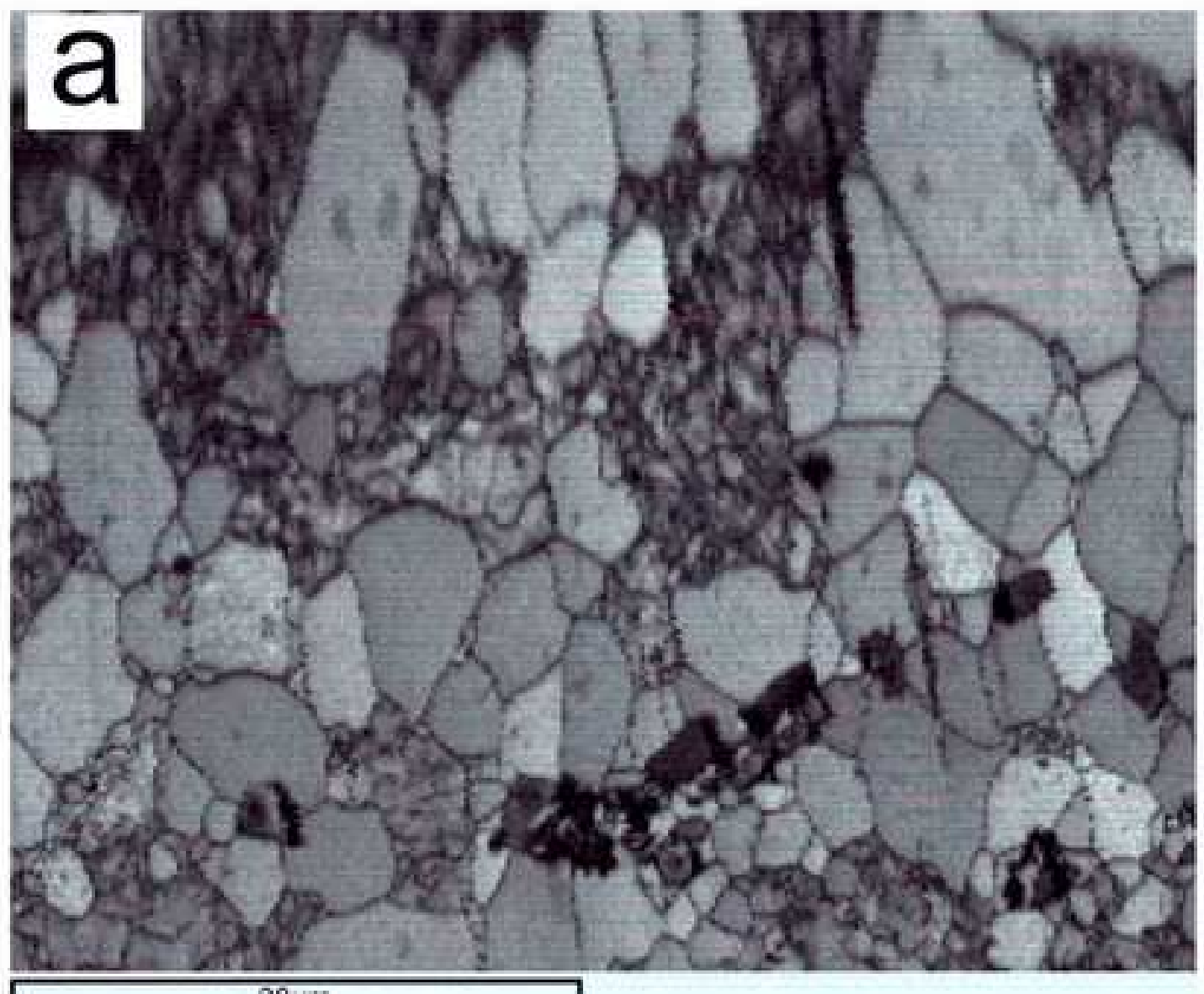

30um

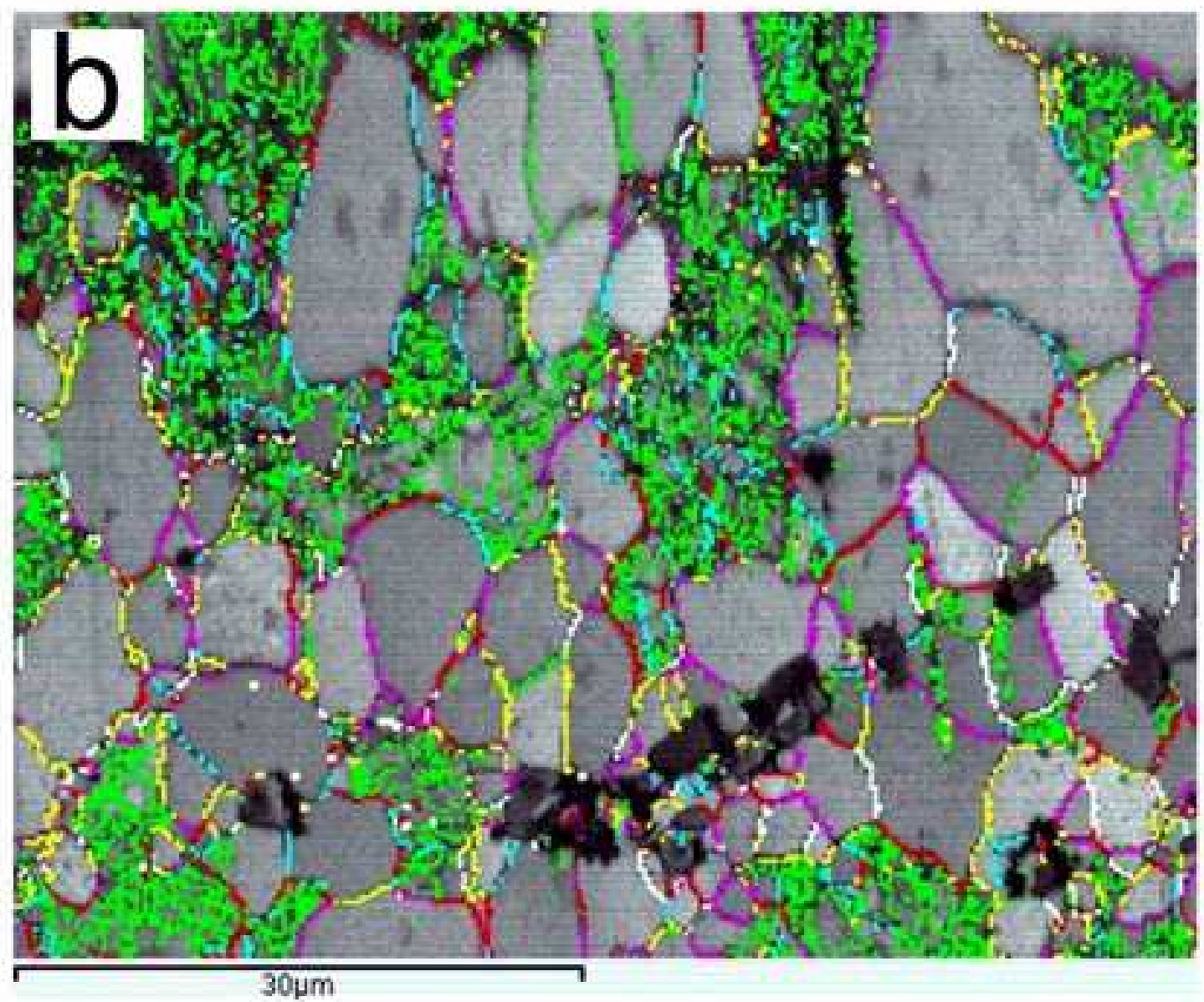


Click here to download high resolution image
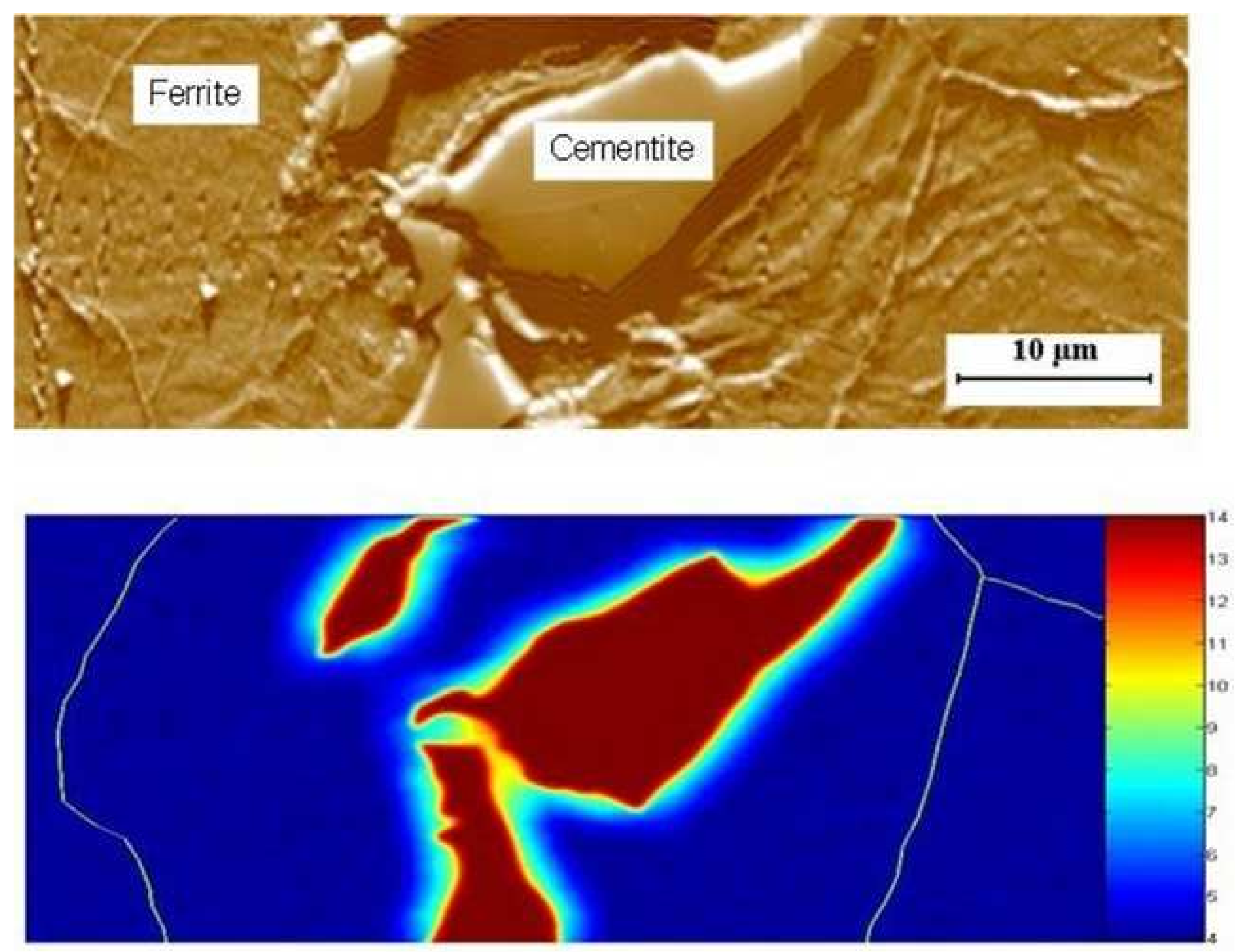

GPa

\section{Cementite}

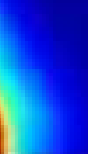



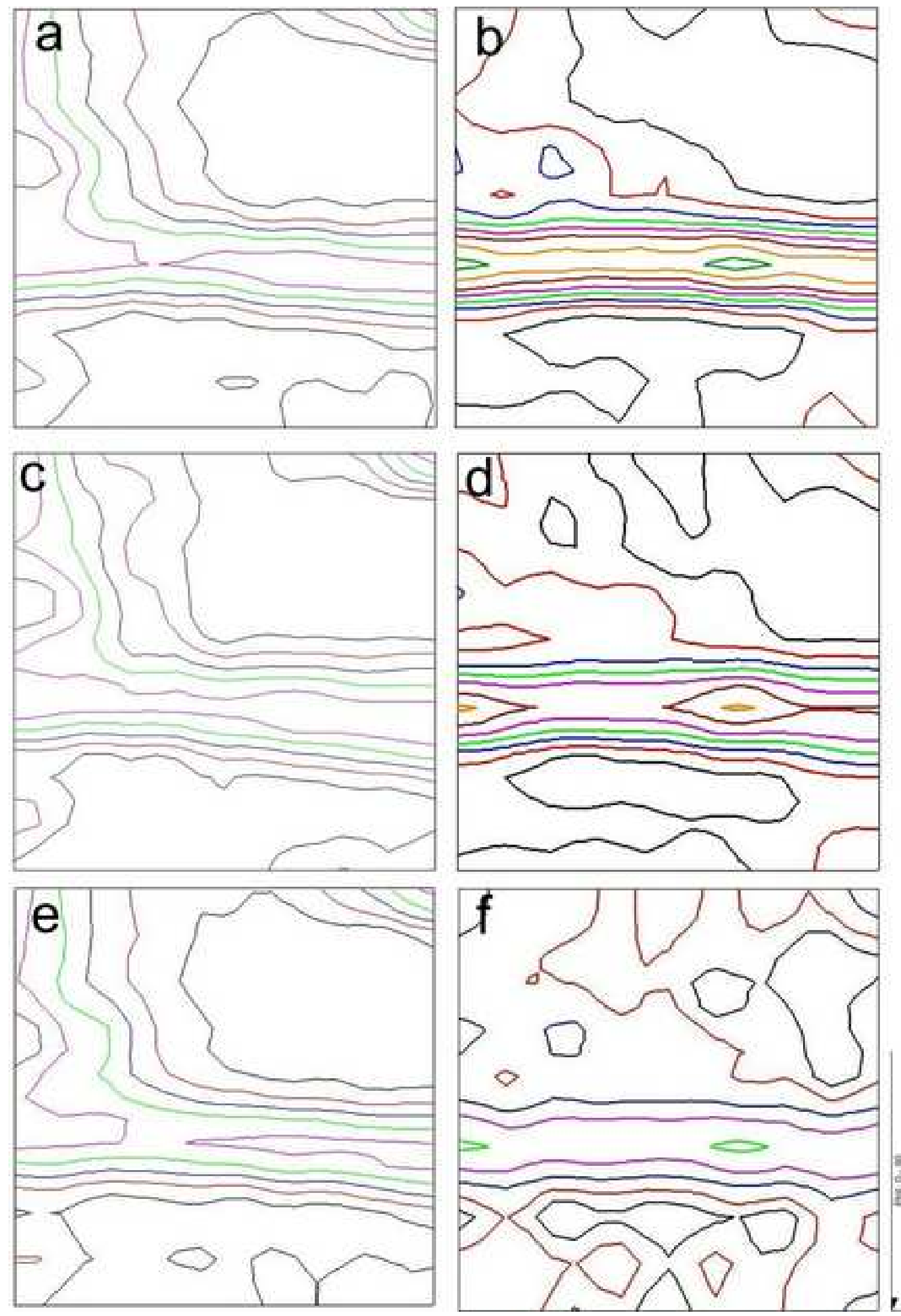

$0.80=$
$1.00=$
$2.40=$
$3.20=$
$4.00=$
$4.80=$
$5.60=$
$6.40=$ 


\section{Figure 7}

Click here to download high resolution image

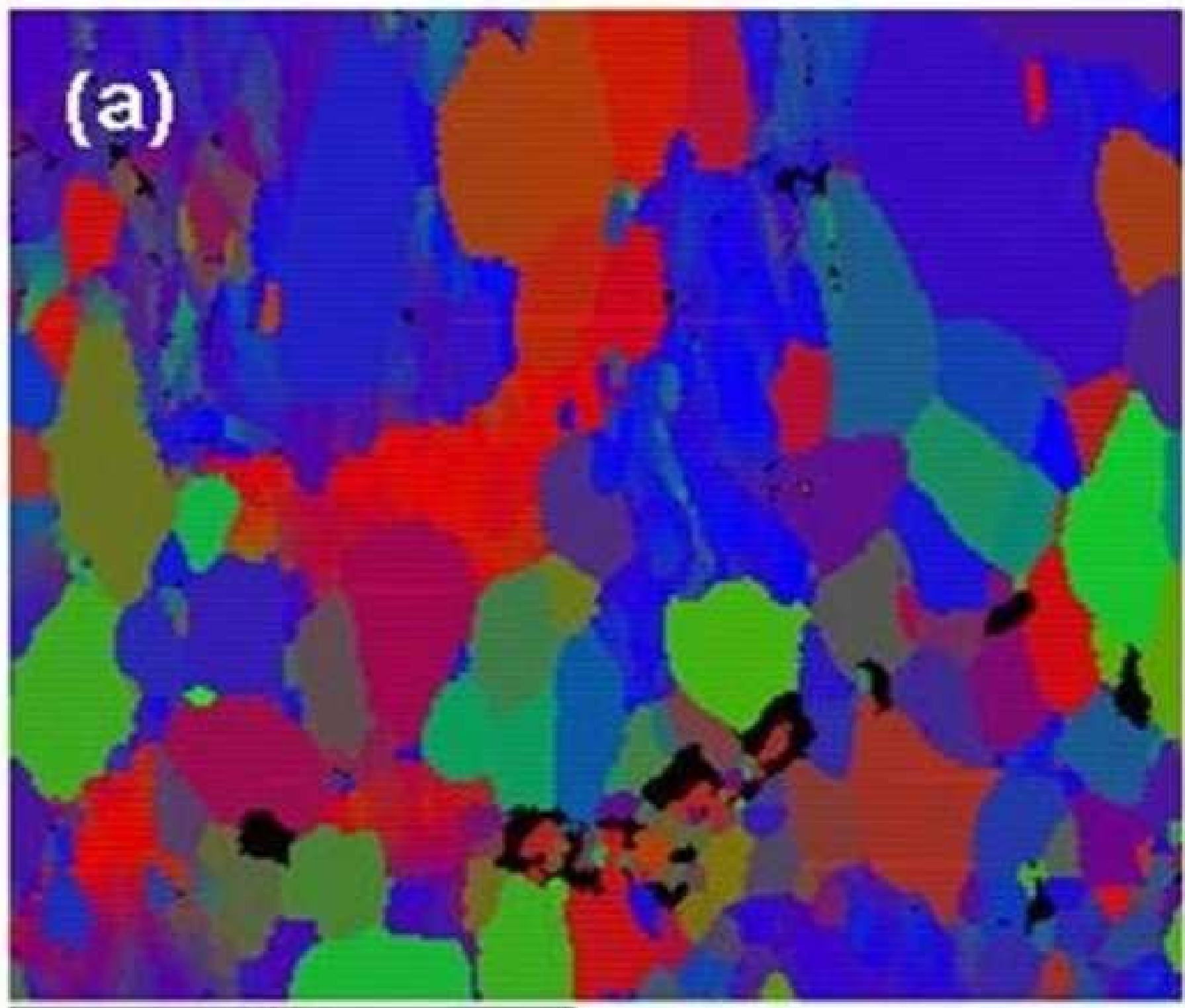

30 ym
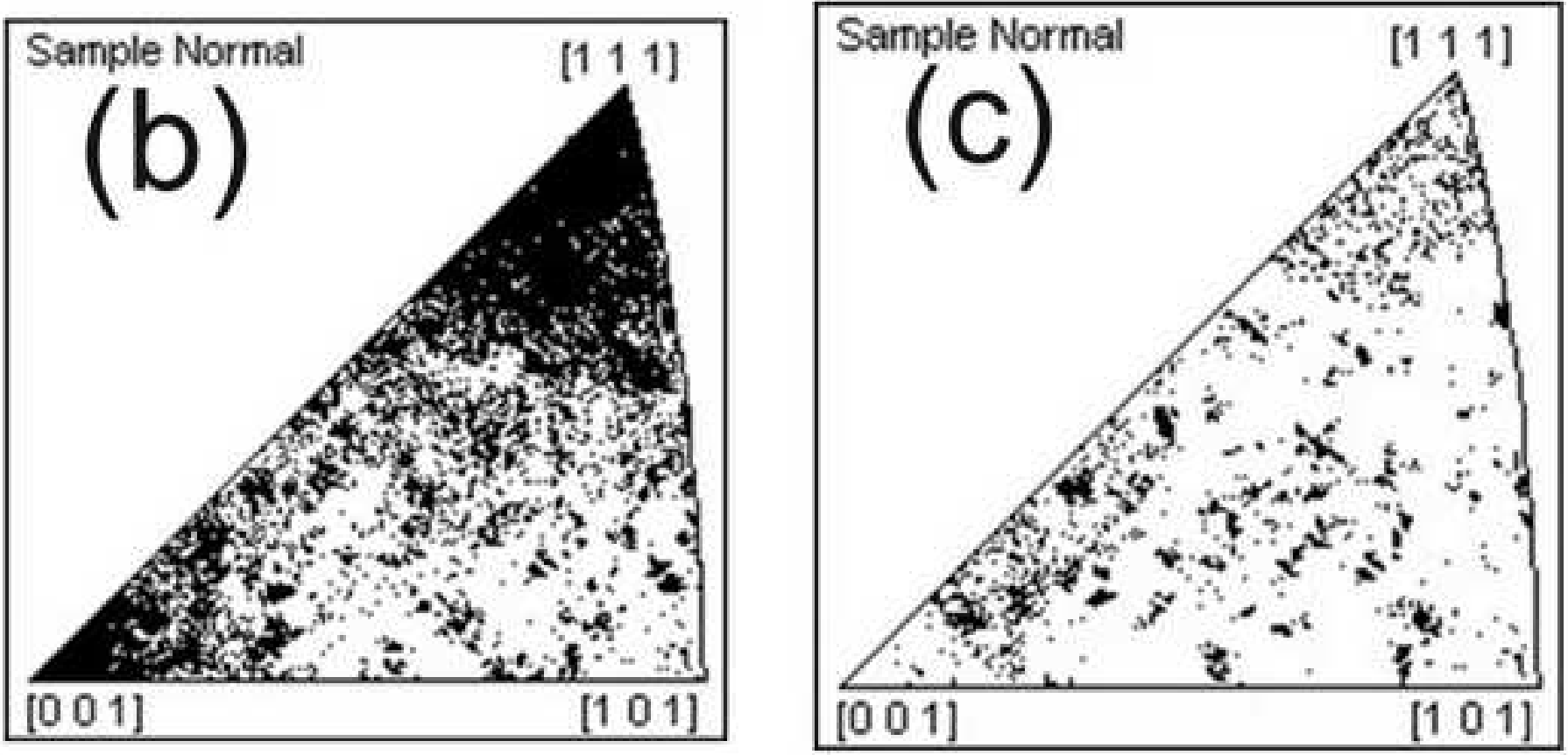
Figure 8
Click here to download high resolution image

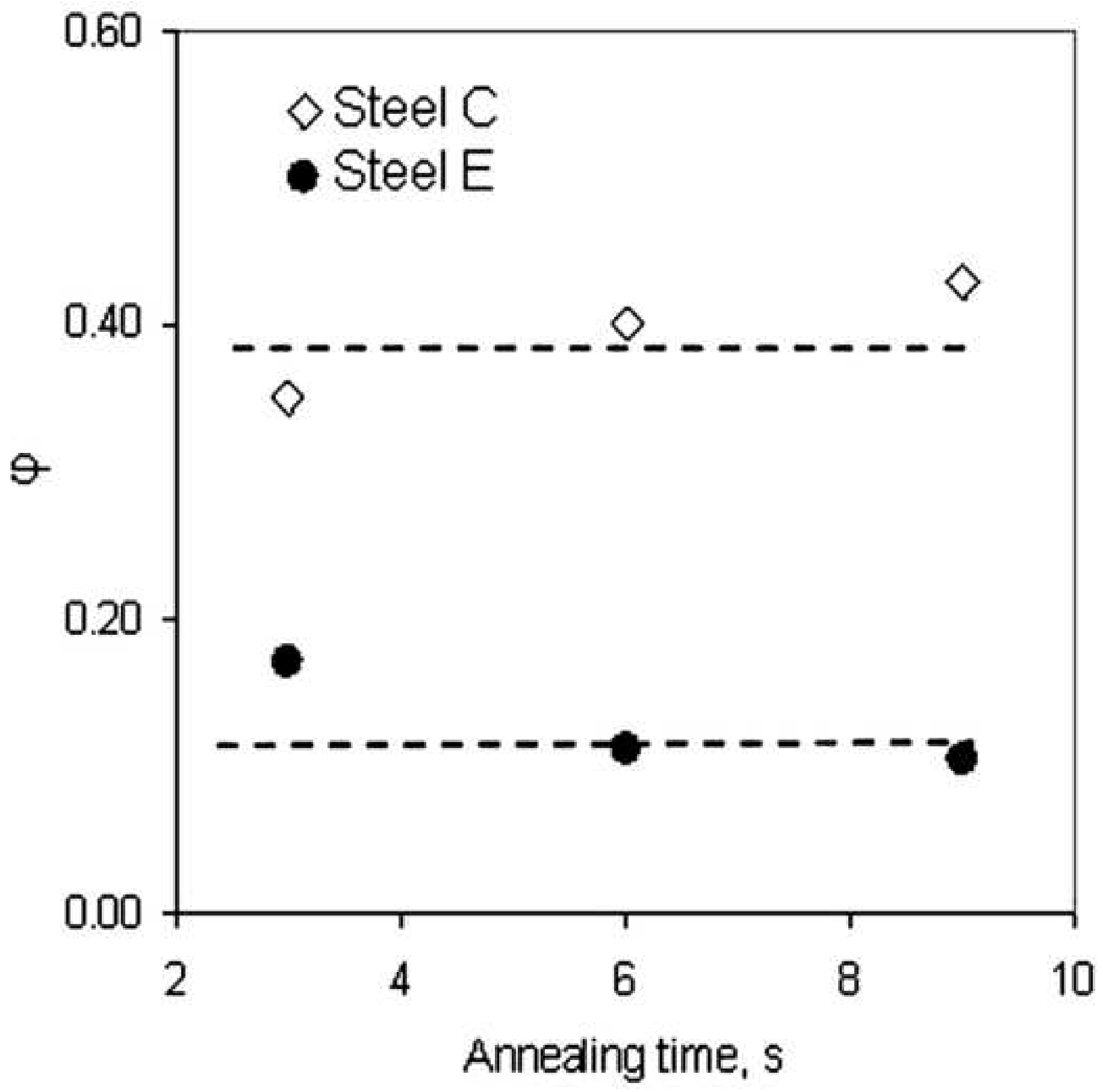


Click here to download high resolution image
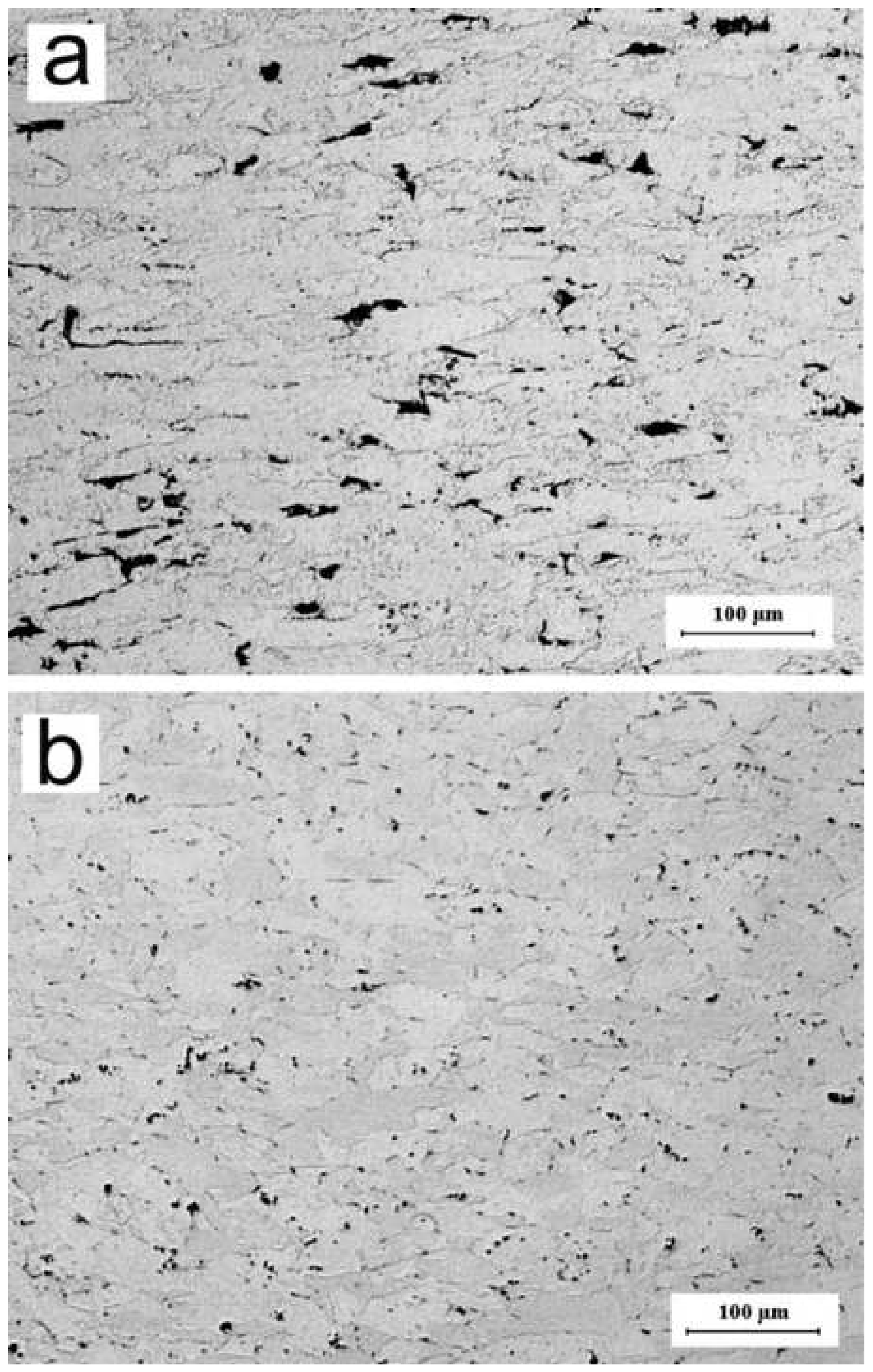


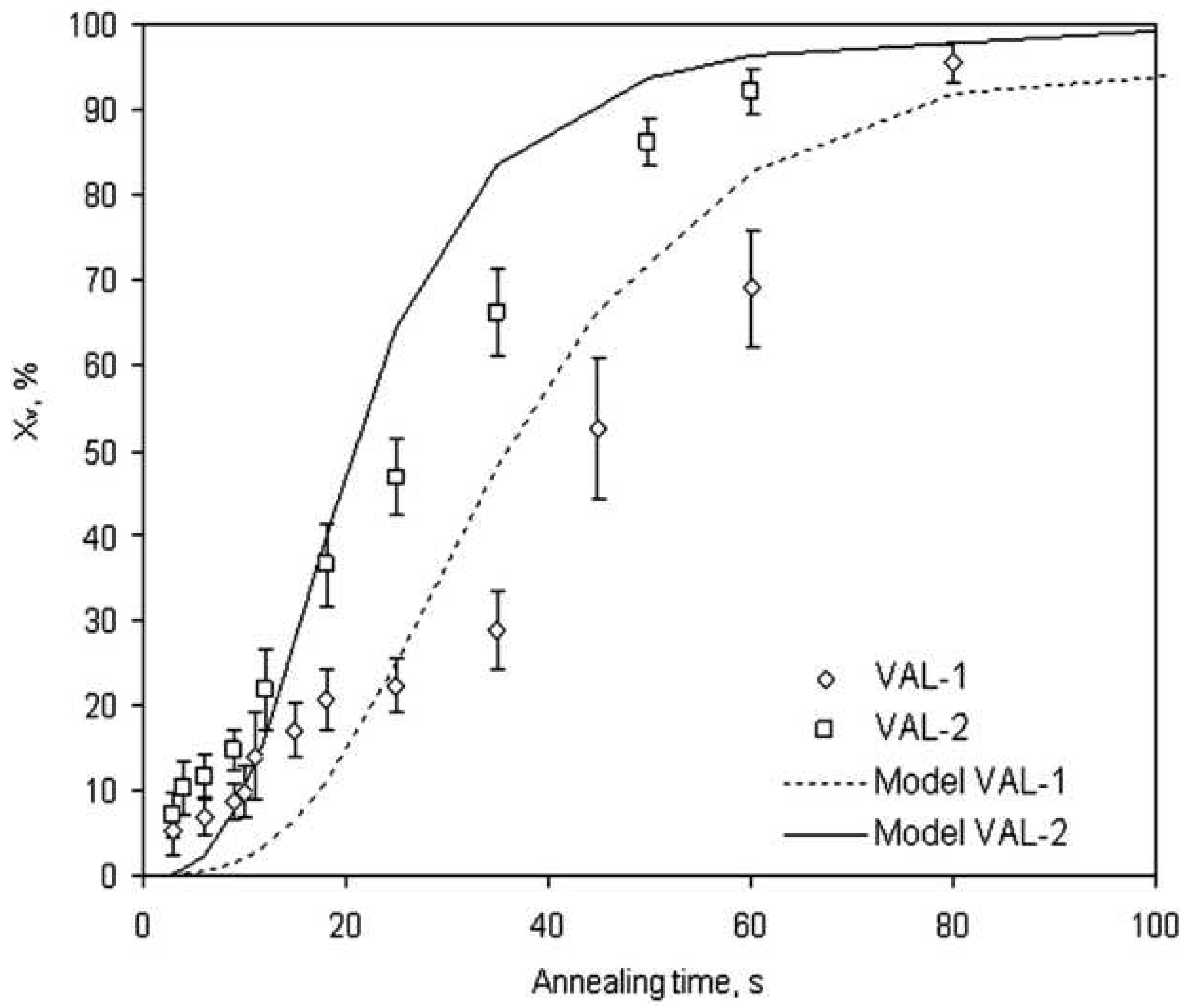




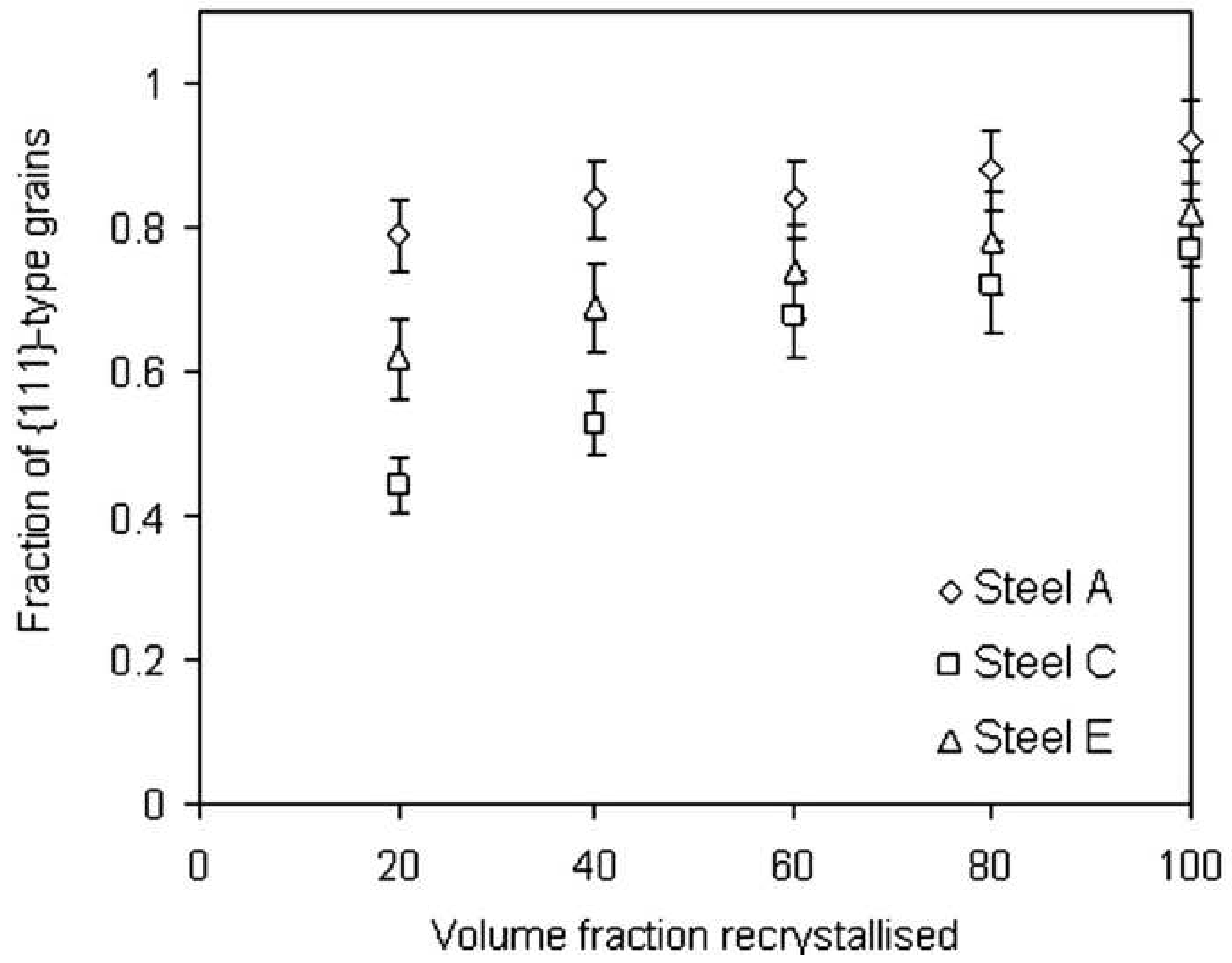




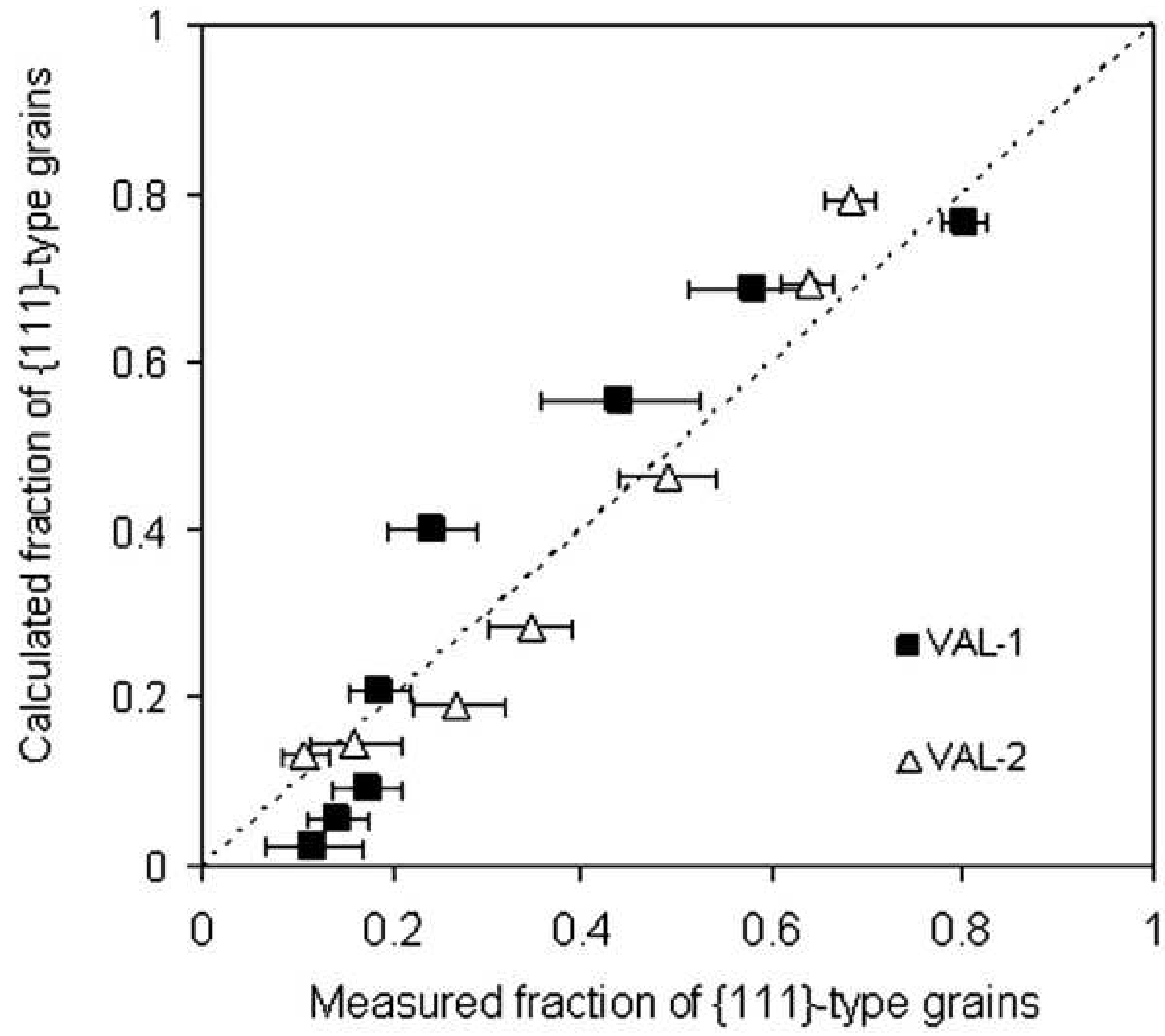

